Research Article

\title{
Coordination of Time-Varying Price Supply Chain with Risk-Averse Members under Random Order Response Time
}

\author{
Shuanjun Song $\mathbb{D}^{1,2}$ Minyan Zhang, ${ }^{1,2}$ and Sheng $\mathrm{Hu}^{1,2}$ \\ ${ }^{1}$ School of Mechanical \& Electrical Engineering, Xi'an Polytechnic University, Xi'an 710048, China \\ ${ }^{2} X i$ 'an Key Laboratory of Modern Intelligent Textile Equipment, Xi'an 710048, China \\ Correspondence should be addressed to Shuanjun Song; songshuanjun@126.com
}

Received 25 September 2019; Revised 15 January 2020; Accepted 3 February 2020; Published 25 February 2020

Academic Editor: Anna M. Gil-Lafuente

Copyright $\left({ }_{0} 2020\right.$ Shuanjun Song et al. This is an open access article distributed under the Creative Commons Attribution License, which permits unrestricted use, distribution, and reproduction in any medium, provided the original work is properly cited.

A joint contract is proposed to coordinate the time-varying supply chain of risk-averse manufacturers and retailers. The joint contract uses price reduction subsidies and revenue-sharing strategies to enable manufacturers and retailers to share risks and achieve overall coordination of the supply chain. Firstly, a centralized and a decentralized decision-making model of the riskaverse supply chain are established. On this basis, reasons for the supply chain failure to coordinate are analyzed, and a joint contract is designed. Then, the specific form of the joint contract is given. Finally, the coordination effect of the joint contract is quantitatively analyzed through numerical analysis.

\section{Introduction}

With the shortening of product renewal cycle, product competitiveness is not only related to price and quality but also closely related to order response time. Time-based competition mode [1] has become the main mode of product competition. Therefore, in the coordinated operation of the supply chain, each node enterprise distributed in the product life cycle must consider the time parameter as the main factor of decision-making. In reality, market demand, manufacturing cost, product price, and other important parameters [2-15] in supply chain operation will vary with time, so it is necessary to consider the time-varying characteristics in the process of supply chain operation. On the contrary, in the actual operation of the supply chain, the decision makers are not completely rational, and they often have a certain risk preference [16-26]. There are obvious differences between the final decision-making and the ideal decision-making of decision makers with different risk preference attitudes. This difference will ultimately affect the performance and coordination of the supply chain. Therefore, in the actual operation of the supply chain, considering the time-varying characteristics of the supply chain and the risk preference characteristics of its members will help decision makers to obtain the optimal decision-making plan and make the supply chain reach actual optimal performance. The contribution of this paper is to design a new coordination contract which considers the risk preference of supply chain members and time-varying characteristics. By this way, in the coordinated operation of the supply chain, we can get the best decision which is suitable for the actual operation of the supply chain.

The time-varying characteristics of the supply chain are mainly studied from time-varying factors such as market price, cost, order decision, order demand, prediction accuracy, response time delay, and certain randomness, [1-5]. Chen and Chou [5] studied the multilayer supply chain network with time-varying market demand and related costs and described the dynamic law of price and order decisionmaking of supply chain members with time by establishing a model. Nagurney et al. [6] studied the equilibrium decisionmaking problem of the power supply chain network with time-varying consumer demand from the perspective of consumers. However, both Chen's and Nagurney et al.'s studies assumed that there is no response time delay among supply chain members. For general industrial products, there is a response time delay among supply chain network members, and the response time is random. Peng and Zhang 
[7] expanded the research results of Chen and Nagurney et al.'s study, focusing on how the response time delay among supply chain members affects the decision-making of supply chain members. Su et al. [8] considered the optimization of short-life supply chain with time-varying forecasting accuracy and cost and proposed that the dynamic wholesale price contract combined with order feedback and penalty could achieve all-win situation for supply chain members. Assuming that demand and price are time-sensitive, Hou and Qiu [9] reconstructed the option contract model of the supply chain, which proved that the option contract was effective in coordinating such supply chain. The influence of time-varying characteristics on the coordinated operation of the supply chain is also considered in the literature [10-15]. It can be seen that time-varying characteristics in supply chain operation have a significant impact on supply chain coordination and member decisionmaking, which should be fully considered in supply chain coordination operation.

In the supply chain coordinating, in addition to the timevarying characteristics of the supply chain, the risk preference of supply chain members will also have an impact on the supply chain coordination decision-making and final performance. The same coordination strategy will have different coordination effects for supply chain members with different risk attitudes. In order to be close to the reality of supply chain management, many scholars have considered the risk preference of supply chain members in the establishment of the supply chain decision-making model in recent years. Ye and Lin [16] studied the incentive problem of two-level supply chain cooperation composed of riskaverse retailers and risk-averse suppliers and proposed that revenue-sharing contracts could be used to coordinate such supply chains. Lin et al. [17] re-established the revenuesharing contract model based on the risk measurement criteria of conditional risk valuation. Wang and Zhou [18] discussed the optimal strategy of the dual-channel supply chain when the decision maker is risk-averse. By means of mean-variance analysis, Zhang and Yao [19] studied the optimal strategy of the two-channel supply chain when customers returned goods. At the same time, some literature studies [20-26] have been carried out on the closed-loop supply chain decision-making model considering risk aversion. However, the above literature studies only consider the impact of risk aversion characteristics of supply chain members on decision-making parameters, while the timevarying characteristics of the supply chain are ignored. In addition, the modeling method is more complex.

Different from the above research, this paper comprehensively considers the time-varying characteristics and riskaversion characteristics in the actual operation of the supply chain and re-establishes the supply chain decision-making model. The model uses prospect theory as a risk measurement tool, taking into account the double randomness of market demand and order response time. On this basis, we design a joint contract of price reduction subsidy and revenue sharing based on order response time and discuss the conditions that the contract parameters should be optimized.

\section{Problem and Symbol Descriptions}

Suppose that a time-varying price supply chain produces a short-life-cycle product. The members of the supply chain are risk-averse and consist of a single manufacturer and retailer. At the same time, the order response time of manufacturers is certainly random, and the market price of the product falls with time. Retailers determine the order quantity based on their risk aversion, market demand forecast, and manufacturers' order response time. Manufacturers determine other contract parameters based on their risk aversion. Given the symmetry of information, both manufacturers and retailers have access to private information such as product demand, price, and market demand. Manufacturers and the retailer are the "master" and "slave" relationships in the Stackelberg game.

According to modeling needs, some parameters and variables are defined, as shown in Table 1 . The distribution function $F(x)$ and $U(t)$ are assumed to be continuous, differentiable, monotonically increasing, $F(x)>0, f(x)>0$, $U(t)>0, u(t)>0, p$ decreases exponentially with $t, p(t)=$ $p_{0} e^{-\beta t}$ (the same expression is also used in the literature [27]), $\lim _{t \rightarrow 0} p(t)=p_{0}, \beta$ is the sensitivity coefficient of market price to response time, and $p(t)>c_{s}$. $P$ is the expected market price of a unit product, $P=E(p)=\int_{0}^{\tau} p_{0} e^{-\beta t} u(t) \mathrm{d} t . \mathrm{g}$ is the unit residual value, $g<p_{0} e^{-\beta t}$; out of stock loss is not considered here. $\pi$ is the actual profit of the supply chain. In the following text, the subscript $j$ denotes the centralized system, $f$ denotes the decentralized system, $h$ denotes the cooperative system, and the superscript ${ }^{*}$ denotes the optimal value.

\section{Optimal Decision Model for the Centralized System}

In a centralized system, if the supply chain is risk-averse, the risk-averse degree of the supply chain is determined by the risk-averse characteristics of manufacturers and retailers. Referring to the hypothesis in [15], the risk-averse coefficient of the whole supply chain system can be described as

$$
\lambda=\gamma \lambda_{r}+(1-\gamma) \lambda_{s} .
$$

In formula (1), $\gamma$ is determined by the influence of manufacturers and the retailer in the supply chain system, $\gamma \in[0,1]$. The larger $\lambda$, the greater the degree of risk aversion in the supply chain system; the smaller $\lambda$, the smaller the degree of risk aversion in the supply chain system. $\lambda \geq 1$, when $\lambda=1$, the supply chain system is risk neutral. According to the prospect theory [28], the utility function of the supply chain can be expressed by formula (2). The decision goal of the centralized system is to maximize the expected utility of the whole supply chain system. 
TABLE 1: Symbol notation.

\begin{tabular}{lc}
\hline Symbol & Notation \\
\hline$x$ & Market demand, $x>0$ \\
$F(x)$ & Cumulative distribution function of $x$ \\
$f(x)$ & Probability density function of $x$ \\
$c_{s}$ & Manufacturers' unit production cost \\
$c_{r}$ & Retailer' unit marginal cost \\
$w$ & Manufacturers' unit wholesale price \\
$W$ & Manufacturers' expected wholesale price \\
$g$ & Unit residual value \\
$q$ & Order quantity \\
$t$ & Response time, $t \in[0, \tau]$ \\
$U(t)$ & Cumulative distribution function of $t$ \\
$u(t)$ & Probability density function of $t$ \\
$U_{r}$ & Retailer's utility function \\
$U$ & Utility of the whole supply chain \\
$p$ & Price of unit products \\
$p_{0}$ & Price of unit products as $t=0$ \\
$P$ & Expected price of unit products \\
$\beta$ & Sensitivity of $p$ to $t$ \\
$\lambda$ & Risk aversion coefficient of the supply chain \\
$\lambda_{s}$ & Risk aversion coefficient of manufacturers \\
$\lambda_{r}$ & Risk aversion coefficient of the retailer \\
$\Pi_{s}$ & Manufacturers' expected profit \\
$\Pi_{r}$ & Retailers' expected profit \\
$\Pi$ & Sxpected profit of the supply chain \\
$\alpha$ & Revenue-sharing ratio \\
$\phi$ &
\end{tabular}

$$
\begin{aligned}
U= & \begin{cases}\pi, & \pi \geq 0, \\
\lambda \pi, & \pi<0,\end{cases} \\
E(U)= & \int_{0}^{A} \lambda\left[P x+g\left(q_{j}-x\right)-\left(c_{s}+c_{r}\right) q_{j}\right] f(x) \mathrm{d} x \\
& +\int_{A}^{q_{j}}\left[P x+g\left(q_{j}-x\right)-\left(c_{s}+c_{r}\right) q_{j}\right] f(x) \mathrm{d} x \\
& +\int_{q_{j}}^{\infty}\left(P-c_{s}-c_{r}\right) q_{j} f(x) \mathrm{d} x,
\end{aligned}
$$

where $A=\left(\left(c_{s}+c_{r}-g\right) q_{j}\right) /(P-g)$.

$$
\begin{aligned}
\frac{\partial E(U)}{\partial q_{j}} & =(1-\lambda)\left(c_{s}+c_{r}-g\right) F(A)+\left(P-c_{s}-c_{r}\right) \\
& -(P-g) F\left(q_{j}\right), \\
\frac{\partial^{2} E(U)}{\partial q_{j}^{2}} & =-\frac{(\lambda-1)\left(c_{s}+c_{r}-g\right)^{2}}{(P-g)} f(A)-(P-g) f\left(q_{j}\right)<0 .
\end{aligned}
$$

Formula (5) shows that the expected utility of the centralized system is a concave function of the order quantity. The optimal order quantity satisfies the following relationship:

$$
F\left(q_{j}^{*}\right)=\frac{\left(P-c_{s}-c_{r}\right)-(\lambda-1)\left(c_{s}+c_{r}-g\right) F\left(A^{*}\right)}{P-g},
$$

where $A^{*}=\left(\left(c_{s}+c_{r}-g\right) q_{j}^{*}\right) /(P-g)$ 。
According to formula (6), we can get $\left(\left(\partial F\left(q_{j}^{*}\right)\right) / \partial \lambda\right)=$ $\left(\left(-\left(c_{s}+c_{r}-g\right) F\left(A^{*}\right)\right) /(P-g)\right)<0$, so $F\left(q_{j}^{*}\right)$ decreases with the increase of $\lambda$ and decreases monotonously. Because $F(x)$ is an incremental function, $q_{j}{ }^{*}$ decreases with the increase of $\lambda$. Because $\lambda \geq 1$, when $\lambda=1, q_{j}$ achieves the maximum, and the corresponding order quantity is the optimal order quantity of the risk-neutral supply chain in the centralized system. Based on this, we can see that the optimal order quantity of the risk-averse supply chain decreases with the increase of risk-averse degree in the centralized system and does not exceed the optimal order quantity of the riskneutral supply chain.

\section{Optimal Decision Model for Decentralized Systems}

In the decentralized system, risk aversion manufacturers make wholesale price $w$ according to their risk aversion degree, manufacturing cost, order response time, price decline trend, retailer's order quantity, and expected profit. At this time, manufacturers' expected profit is

$$
\Pi_{s}=\left(w-c_{s}\right) q_{f} .
$$

At the same time, retailers make optimal order quantity decisions according to the predicted market demand, manufacturers' wholesale price, product price downward trend, manufacturers' order response time, and their risk aversion degree. The decision goal is to maximize their expected utility.

Similarly, retailers' utility and optimal order quantity should satisfy the following formula:

$$
\begin{aligned}
E\left(U_{r}\right)= & \int_{0}^{B} \lambda_{r}\left[P x+g\left(q_{f}-x\right)-\left(w+c_{r}\right) q_{f}\right] f(x) \mathrm{d} x \\
& +\int_{B}^{q_{f}}\left[P x+g\left(q_{f}-x\right)-\left(w+c_{r}\right) q_{f}\right] f(x) \mathrm{d} x \\
& +\int_{q_{f}}^{\infty}\left(P-w-c_{r}\right) q_{f} f(x) \mathrm{d} x, \\
F\left(q_{f}^{*}\right)= & \frac{\left(P-w-c_{r}\right)-\left(\lambda_{r}-1\right)\left(w+c_{r}-g\right) F\left(B^{*}\right)}{P-g},
\end{aligned}
$$

where $B=\left(\left(w+c_{r}-g\right) q_{f}\right) /(P-g), B^{*}=\left(\left(w+c_{r}-g\right) q_{f}^{*}\right) /$ $(P-g)$ 。

In decentralized systems, because retailers take the uncertain risk of manufacturers' delivery date and market demand, their optimal order quantity is far less than the overall optimal order quantity of the supply chain, so the supply chain cannot be coordinated. This has been proved in the literature [29].

\section{Coordination Contract Design for the Cooperative System}

To adjust the proportion of retailers taking risks in the decentralized system, we adopt the following strategies. For 
the uncertainty risk of manufacturers' delivery date, the wholesale price of manufacturers decreases with the actual response time $t$, which is a decrease function of the actual response time expressed by $w(t), t \in[0, \tau]$. Manufacturers' expected wholesale price is

$$
W=\int_{0}^{\tau} w(t) u(t) \mathrm{d} t
$$

In this way, when the actual delivery occurs, manufacturers give retailers a certain price compensation for the price reduction loss caused by the time-varying price. For the risk of uncertain market demand, manufacturers set wholesale prices below their manufacturing costs and adopt revenue-sharing contracts to share risks with retailers. So, retailers' ordering behavior is also encouraged. We call the contract formed by this strategy the joint contract of price reduction subsidy and revenue sharing based on order response time.

Next, we discuss the specific form of the joint contract. Firstly, manufacturers and retailers sign a revenue-sharing contract. The contract parameters are the basic wholesale price $w$ and revenue-sharing ratio $\phi$. Among them, retailers' share of sales revenue is $\phi(0<\phi<1)$, and manufacturers' share is $1-\phi$.

Under the revenue-sharing contract, the expected utility of risk aversion retailers can be described as

$$
\begin{aligned}
E\left(U_{r}\right)= & \int_{0}^{A_{1}} \lambda_{r}\left[\phi P x-\left(W+c_{r}\right) q_{h}+g\left(q_{h}-x\right)\right] f(x) \mathrm{d} x \\
& +\int_{A_{1}}^{q_{h}}\left[\phi P x-\left(W+c_{r}\right) q_{h}+g\left(q_{h}-x\right)\right] f(x) \mathrm{d} x \\
& +\int_{q_{h}}^{\infty}\left(\phi P-W-c_{r}\right) q_{h} f(x) \mathrm{d} x,
\end{aligned}
$$

where $A_{1}=\left(\left(W+c_{r}-g\right) q_{h}\right) /(\phi P-g)$. From formula (9), we can get that

$$
\begin{aligned}
\frac{\partial E\left(U_{r}\right)}{\partial q_{h}}= & \left(1-\lambda_{r}\right)\left(W+c_{r}-g\right) F\left(A_{1}\right)+\left(\phi P-W-c_{r}\right) \\
& -(\phi P-g) F\left(q_{h}\right), \\
\frac{\partial^{2} E\left(U_{r}\right)}{\partial q_{h}^{2}}= & -\frac{\left(\lambda_{r}-1\right)\left(W+c_{r}-g\right)^{2}}{(\phi P-g)} f\left(A_{1}\right)-(\phi P-g) f\left(q_{h}\right)<0 .
\end{aligned}
$$

Therefore, it can be seen that, under the revenue-sharing contract, retailers with risk aversion have the optimal order quantity to maximize their utility. At this time, the optimal order quantity should satisfy the following relations:

$$
F\left(q_{h}^{*}\right)=\frac{\left(\phi p-W^{*}-c_{r}\right)-\left(\lambda_{r}-1\right)\left(W^{*}+c_{r}-g\right) F\left(A_{1}^{*}\right)}{\phi p-g},
$$

where $A_{1}^{*}=\left(\left(W^{*}+c_{r}-g\right) q_{h}^{*}\right) /(\phi p-g) \circ$ Namely, $F\left(q_{j}{ }^{*}\right)$ $=F\left(q_{h}^{*}\right)$, and we can get that

$$
W^{*}=\phi p-c_{r}-(\phi p-g) F\left(q_{j}^{*}\right)-\left(\lambda_{r}-1\right)\left(W^{*}+c_{r}-g\right) F\left(A_{1}^{*}\right) .
$$

Since manufacturers' actual order response time is delayed by $t$, it will inevitably lead to the loss of product price. The loss is $p_{0}-p_{0} e^{-\beta t}$. In order to compensate for this loss, manufacturers give retailers a certain subsidy, assuming that the subsidy ratio is $\alpha(\alpha \in[0,1])$. Then, the wholesale price of manufacturers should be reduced by $\alpha\left(p_{0}-p_{0} e^{-\beta t}\right)$. Therefore, when the actual order response time of manufacturers is $t$, the specific form of the wholesale price of manufacturers is as follows:

$$
w(t)=w-\alpha\left(p_{0}-p_{0} e^{-\beta t}\right) .
$$

Under the joint contract, when retailers' order quantity is $q_{h}$, the expected profit of manufacturers $\left(\Pi_{s}^{\prime}\right)$ and retailers $\left(\Pi_{r}^{\prime}\right)$ can be described as

$$
\begin{aligned}
\Pi_{s}^{\prime}= & (1-\phi) P\left[q_{h}-\int_{0}^{q_{h}}\left(q_{h}-x\right) f(x) \mathrm{d} x\right]+\left(W-c_{s}\right) q_{h} \\
= & {\left[(1-\phi) P+W-c_{s}\right] q_{h}-(1-\phi) P \int_{0}^{q_{h}}\left(q_{h}-x\right) f(x) \mathrm{d} x, } \\
\Pi_{r}^{\prime}= & \phi P\left[q_{h}-\int_{0}^{q_{h}}\left(q_{h}-x\right) f(x) \mathrm{d} x\right]-\left(W+c_{r}\right) q_{h} \\
& +g \int_{0}^{q_{h}}\left(q_{h}-x\right) f(x) \mathrm{d} x \\
= & \left(\phi P-W-c_{r}\right) q_{h}-(\phi P-g) \int_{0}^{q_{h}}\left(q_{h}-x\right) f(x) \mathrm{d} x .
\end{aligned}
$$

Next, we use a numerical example to analyze the coordination effect of this joint contract in a time-varying price supply chain with risk-averse members.

\section{A Numerical Example}

Suppose a two-stage supply chain consists of a manufacturer and a retailer. The products produced by the two-stage supply chain have time-varying price characteristics. The manufacturers are the leader, and the members of the supply chain have risk-averse characteristics. $p(t)=400 e^{-0.005 t}$; manufacturers' delivery date (in weeks) follows a uniform distribution, $t \sim U[2,10] . x \sim U[0,1500], c_{r}=20$ (yuan/ pieces), $c_{s}=150$ (yuan/pieces), and $g=50$ (yuan/pieces) suppose there is no shortage loss. In the decentralized decision-making system, the wholesale price given by manufacturers is 240 (yuan/pieces). In the cooperative system, the joint contract of price reduction subsidy and revenue sharing $T(w, \phi, \alpha, q)$ is used between retailers and manufacturers to coordinate the supply chain. Manufacturers set wholesale prices, revenue-sharing ratio, and price reduction subsidy ratio. Retailers decide the order quantity, and both sides make decisions to maximize their utility.

6.1. Decision-Making Results of Different Supply Chain Systems. In order to verify the validity of the joint contract, we first compare the decision-making results of different 
TABLE 2: Decision-making results of different supply chain systems.

\begin{tabular}{|c|c|c|c|c|c|c|c|}
\hline Supply chain system & $q^{*}$ (pieces) & $w$ (yuan/pieces) & $\phi$ & $\alpha$ & $\Pi_{r}($ yuan $)$ & $\Pi_{s}$ (yuan) & $\Pi$ (yuan) \\
\hline Centralized system & 910 & - & - & - & - & - & 105216 \\
\hline Decentralized system & 477 & 240 & - & - & 35497 & 42904 & 78401 \\
\hline Cooperative system & 910 & 75 & 0.5 & 0.5 & 50200 & 55016 & 105216 \\
\hline Profit increment & - & - & - & - & 14703 & 12112 & 26815 \\
\hline Cooperative system & 910 & 82 & 0.55 & 0.5 & 56239 & 48977 & 105216 \\
\hline Profit increment & - & - & - & - & 20742 & 6073 & 26815 \\
\hline Cooperative system & 910 & 74 & 0.5 & 0.55 & 50737 & 54479 & 105216 \\
\hline Profit increment & - & - & - & - & 15240 & 11575 & 26815 \\
\hline
\end{tabular}

decision systems, which is shown in Table 2. Assume that the risk aversion coefficient is $\lambda_{s}=1.5, \lambda_{r}=1.5$, and $\gamma=0.7$.

Comparing the decision-making results in Table 1, we can see that the joint contract consisting of price reduction subsidy and revenue-sharing strategy effectively regulates the risk ratio of retailers and manufacturers in the supply chain. Risk sharing is realized in the operation of the supply chain. The joint contract stimulates retailers' ordering behavior and greatly increases retailers' ordering quantity, thus improving the overall profit of the whole supply chain. It can be seen that the contract increases the profits of both manufacturers and retailers and satisfies individual rational constraints and incentive compatibility constraints. Therefore, this kind of risk aversion and price time-varying supply chain can be effectively coordinated. When the risk aversion degree of supply chain members is determined, in the cooperative system, manufacturers adopt measures such as reducing wholesale prices, increasing price subsidies, and increasing revenue-sharing ratios, which can enable retailers to obtain higher profits. In addition, manufacturers can adjust the revenue ratio of retailers in the supply chain by adjusting the proportion of price reduction subsidies and revenue sharing, which shows that the joint contract has strong flexibility.

6.2. The Influence of Risk Aversion on Contract Parameters. Since there are risk aversion behaviors in the supply chain members, it is necessary to analyze the influence of supply chain members' risk aversion on contract parameters and their profits.

Figure 1 shows the influence of risk aversion on the optimal order quantity. It can be seen that the optimal order quantity of the risk-averse supply chain system under the joint contract is related to the degree of risk aversion in the supply chain and decreases with the increase of risk aversion in the supply chain. In order to further analyze the influence of risk aversion on the profit of different decision-making systems, Figure 2 shows the curve of expected profit of the supply chain in the cooperative system and the decentralized system with the degree of manufacturers' risk aversion when retailers' risk aversion degree is certain $\left(\lambda_{r}=1.5\right)$.

As shown in Figure 2, with the increase of manufacturers' risk aversion, the overall profit of the supply chain of the cooperative system decreases, while the expected profit of the supply chain of the decentralized system remains unchanged. Therefore, when manufacturers' risk aversion increases to a certain extent, the profit of the cooperative

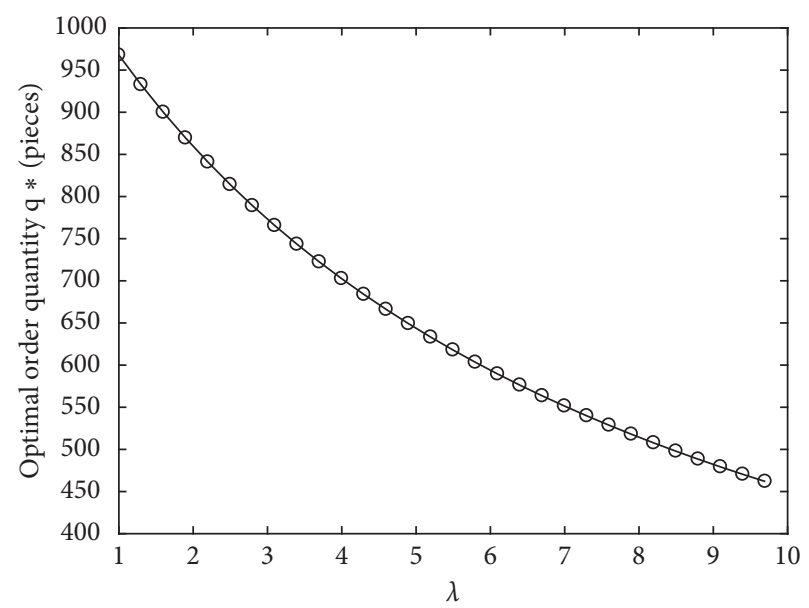

Figure 1: The influence of risk aversion $(\lambda)$ on optimal order quantity $\left(q^{*}\right)$.

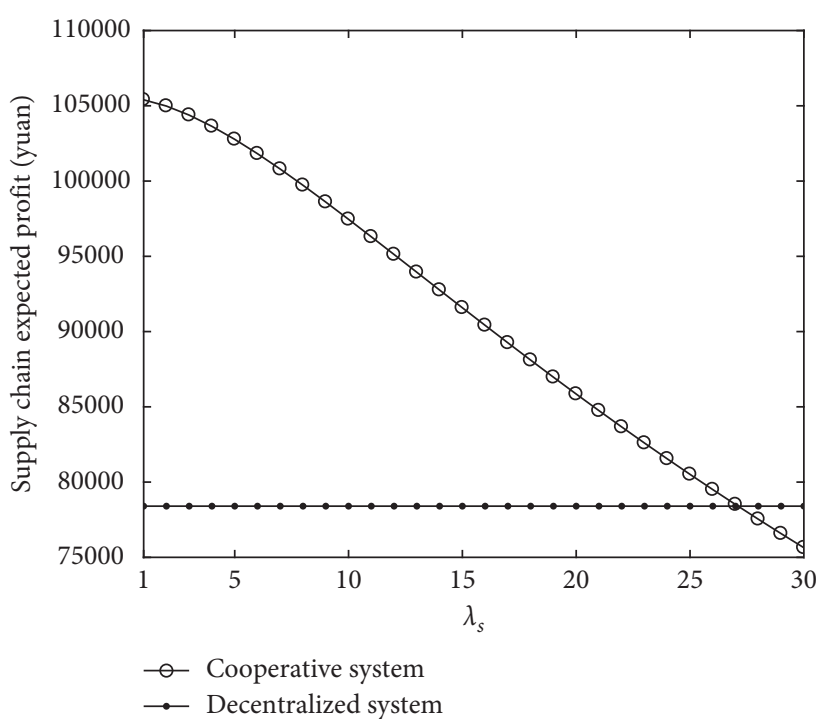

Figure 2: The influence of manufacturers' risk aversion on the profit of the decision-making system.

system will be less than that of the decentralized system, and the joint contract will no longer be valid.

Figure 3 shows the curve of expected profit of different supply chain systems (cooperative system and decentralized system) with retailer's risk aversion when manufacturers' risk aversion is certain $\left(\lambda_{s}=1.5\right)$. It can be seen from 


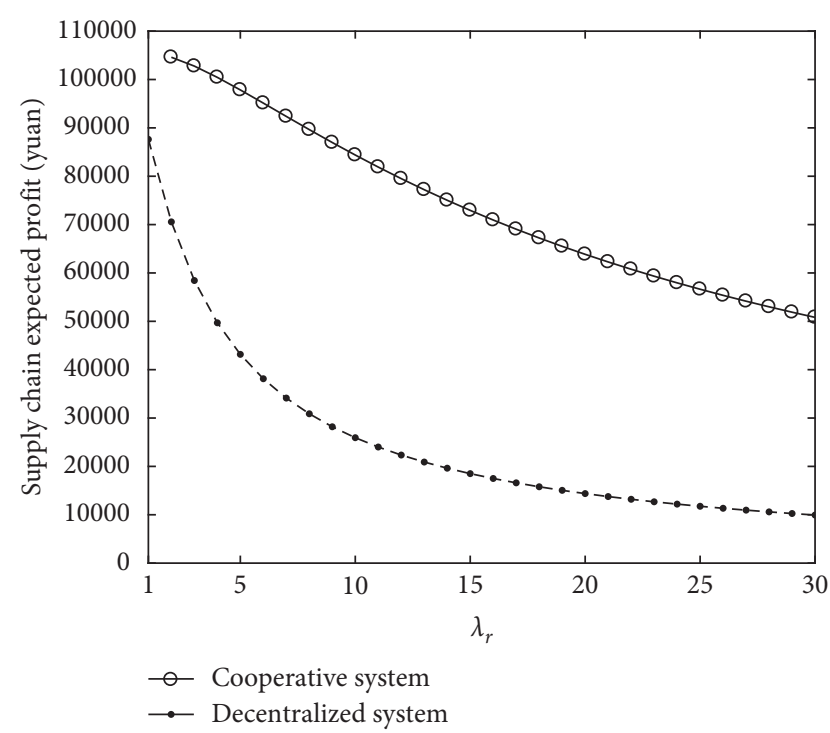

FIGURE 3: The influence of retailer's risk aversion on the profit of the decision-making system.

Figure 3 that, as retailers' risk aversion increases (their ability to withstand risk declines), the expected profits of decentralized and cooperative systems will decrease. However, the expected profit of the cooperative system is always greater than the expected profit of the decentralized system. Therefore, the joint contract is always valid in this case.

Figure 4 shows the optimal basic wholesale price for retailers with different risk aversions under the joint contract. It can be seen that, under the joint contract, the basic wholesale price set by manufacturers is less than the cost price in order to motivate retailers' ordering behavior, and manufacturers share the risk of uncertain market demand with the retailer together. When retailers have a high-risk aversion, only by setting lower wholesale price and taking more risks can manufacturers motivate retailers' ordering behavior.

Figure 5 shows the increment curve of each member's profit relative to the decentralized decision-making system with the increase of retailer's risk aversion under the joint contract. As shown in Figure 5, with the increase of retailer risk aversion, the profit of manufacturers and retailers increases obviously under the joint contract. In most cases, manufacturers' profit has increased more than retailers. In this case, the joint contract is more advantageous to manufacturers.

Figure 6 shows the basic optimal wholesale price set by manufacturers with different risk aversions under the joint contract when retailers' risk aversion degree is certain. Figure 7 shows the increment of expected profits of the supply chain members in the cooperative system relative to the decentralized system. As shown in Figure 6, the higher the risk aversion degree of manufacturers, the higher the basic wholesale price that manufacturers expect to give to retailers. That is to say, due to the increase of risk aversion of manufacturers, manufacturers tend to bear a lower proportion of risk, so they set higher wholesale prices. Under manufacturers' strategy, retailers' order quantity decreases

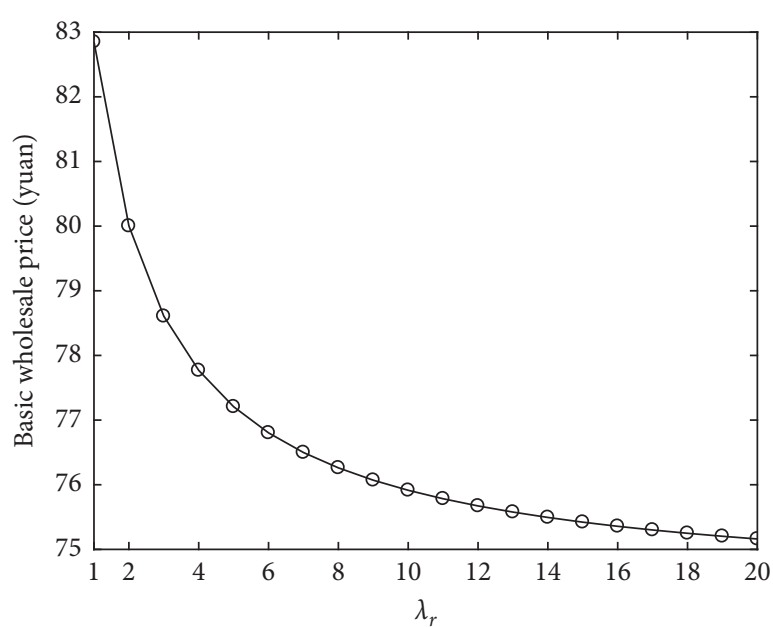

FIGURE 4: The influence of retailer risk aversion on basic wholesale price.

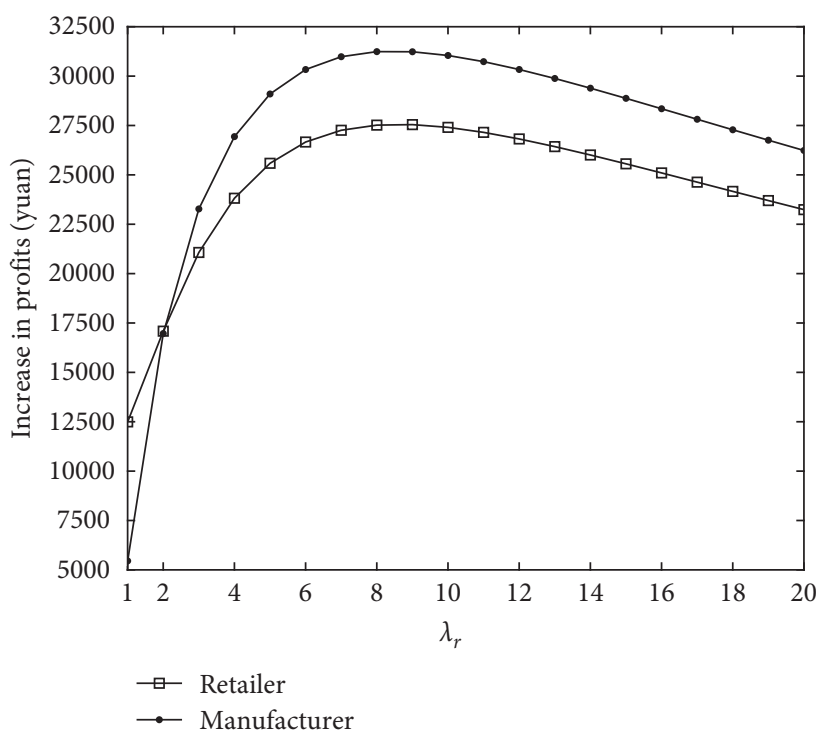

FIGURE 5: Increased profit of members changes with retailer's risk aversion under the joint contract.

and retailers' profit decreases too. When manufacturers' risk aversion degree increases to a certain extent, retailers' expected profit will drop to the level of the decentralized decision-making system (Figure 7), and then the joint contract will be invalid. Therefore, in this case, joint contracts are only suitable for manufacturers with low risk aversion.

6.3. The Influence of Price Reduction Subsidy Coefficient on the Supply Chain. In order to verify the effect of price reduction subsidy strategy on adjusting the risk and profit between the retailer and manufacturers under the joint contract, Figure 8 shows how the expected profit of manufacturers and retailers changes with the price reduction subsidy coefficient when the risk aversion and revenue-sharing ratio are constant $\left(\lambda_{s}=1.5, \lambda_{r}=1.5\right.$, and $\left.\phi=0.5\right)$.

As can be seen from Figure 8, with the increase of manufacturers' price reduction subsidies to retailers, retailers will 


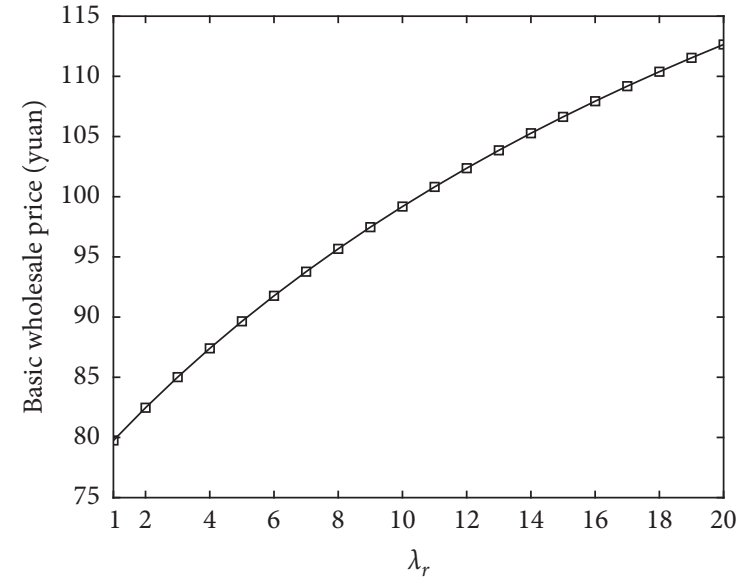

FIGURE 6: The influence of manufacturers' risk aversion on basic wholesale price.

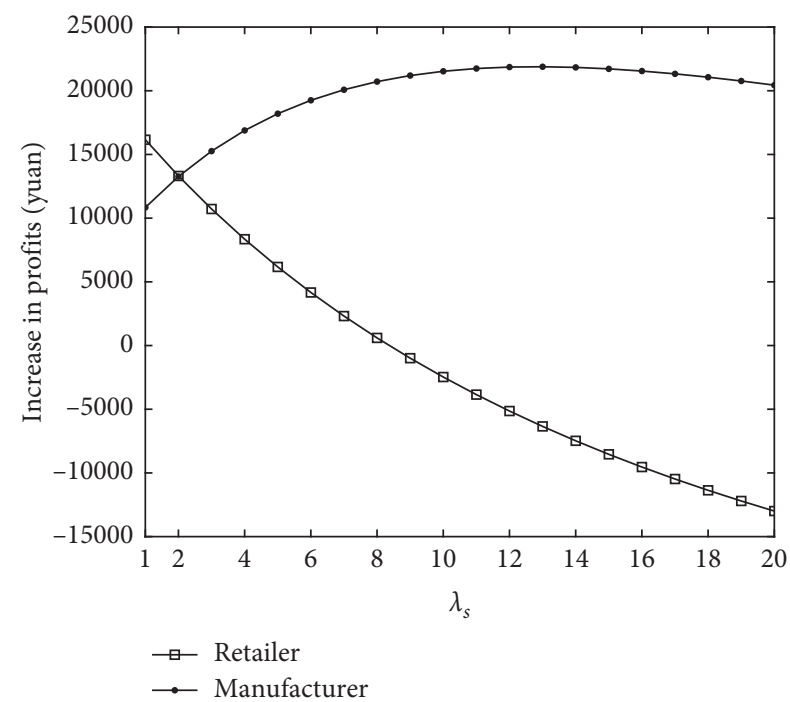

FIGURE 7: Increased profit of members changes with manufacturers' risk aversion under the joint contract.

get more price reduction compensation when actual delivery occurs, and retailers will ultimately get lower wholesale prices than basic wholesale prices. In this way, retailers' profits increase because he has lower purchase costs. At the same time, as the proportion of manufacturers' price reduction subsidies increases, manufacturers' profits will decline. But overall, relative to the decentralized system, the profits of both sides have increased. Thus, manufacturers can adjust the uncertainty risk of order response time in the time-varying supply chain by adjusting the price reduction subsidy coefficient, which shows that the price reduction subsidy strategy is effective.

6.4. The Influence of Response Time on Joint Contract Parameters. In the time-varying price supply chain, the uncertainty order response time of manufacturers will cause the uncertainty of the whole product response cycle, which will affect the final price of the product and the performance of the supply chain. Therefore, it is an important factor

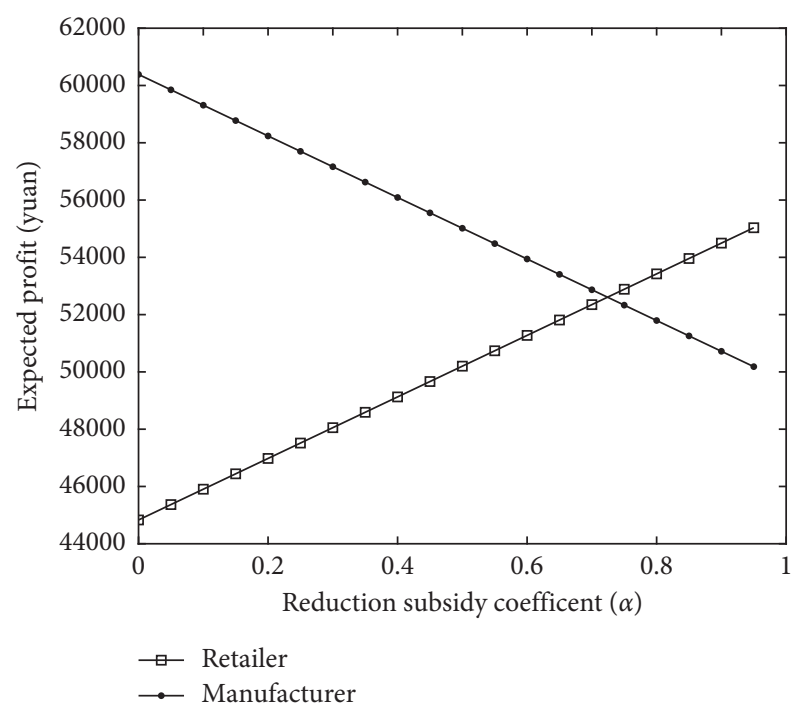

FIgURE 8: The influence of reduction subsidy coefficient on supply chain members' expected profit.

TABLE 3: Influence of uncertain response time on contract parameters.

\begin{tabular}{lcc}
\hline $\begin{array}{l}\text { Range of response } \\
\text { time }\end{array}$ & $\begin{array}{c}\text { Revenue-sharing } \\
\text { coefficient }\end{array}$ & $\begin{array}{c}\text { Basic wholesale } \\
\text { price }\end{array}$ \\
\hline$[2,10]$ & {$[0.334,0.644]$} & {$[58.265,100.964]$} \\
{$[4,10]$} & {$[0.315,0.644]$} & {$[55.577,100.928]$} \\
{$[6,10]$} & {$[0.296,0.644]$} & {$[52.885,100.891]$} \\
{$[8,10]$} & {$[0.277,0.644]$} & {$[50.189,100.854]$} \\
\hline
\end{tabular}

leading to supply chain risk. So, it is worth studying whether the parameters of the joint contract change with the uncertainty of manufacturers' order response time. Table 3 shows the scope of joint contract parameters coordinating the supply chain when manufacturers' order response time is uniformly distributed between $[2,10],[4,10],[6,10]$, and $[8,10]$. When calculating, assume $\lambda_{s}=1.5, \lambda_{r}=1.5$, and $\gamma=0.7$.

From the results of Table 3 , the longer the response time of manufacturers' order, the smaller the wholesale price set by manufacturers, and the wider the revenue-sharing scope between manufacturers and retailers. Because retailers enjoy lower compensation for the loss of price, the revenuesharing ratio of retailers under the joint contract decreases, while manufacturers undertake the contract. It bears a greater risk of falling prices, so it gains a larger share of profits. In addition, it can be seen that, with the increase of the fluctuation of manufacturer's order response time, retailer's expected profit share increases and the scope of joint contract coordination decreases. Therefore, the manufacturer should control the fluctuation of its order response cycle. For the retailer, the shorter the order response cycle, the better for the retailer.

\section{Conclusion}

For a risk-averse supply chain with time-varying price, uncertain market demand, uncertain order response time, 
loss of price due to delayed delivery, and risk attitude of decision makers are all important factors affecting supply chain performance. Based on the comprehensive consideration of the above factors, this paper establishes a decisionmaking model for such a supply chain system. A joint contract of price reduction subsidy and revenue sharing based on order response time is designed to adjust the risk proportion of retailers and manufacturers in the supply chain so as to improve the overall performance of the supply chain. The results show that, in the time-varying price supply chain with risk-averse members, the higher the retailers' risk-averse degree, the more obvious the coordination effect of the joint contract; the smaller the fluctuation of manufacturers' order response time, the more revenue share it will get in the joint contract. Therefore, in the actual supply chain operation, manufacturers should optimize the production plan to reduce the order delay rate. At the same time, manufacturers should improve the awareness of risk sharing and revenue sharing with retailers. Manufacturers should take some measures, such as price reduction subsidy, to encourage retailers' ordering behavior so that both sides can achieve a win-win situation. This paper studies a manufacturer-led supply chain decision system. Future research directions may be retailerled supply chain decision systems. In addition, the paper only considers the time-varying characteristics of prices and does not consider the impact of other parameters' time-varying characteristics on supply chain decisions, which should be the direction of further research.

\section{Data Availability}

The data used to support the findings of this study are included within the article.

\section{Conflicts of Interest}

The authors have declared that no conflicts of interest exist.

\section{Acknowledgments}

This research was supported by the National Science Foundation of China (no. 71271170), Science and Technology Guidance Plan of China Textile Industry Federation (no. 2016090), Doctoral Research Initiation Fund Project of Xi'an Polytechnic University (no. BS201834), and Xi'an Scientific and Technological Innovation Platform Construction Project/Key Laboratory Construction Project (no.2019220614SYS021CG043).

\section{References}

[1] G. Stalk Jr., "Time: the next source of competitive advantage," Harvard Business Review, vol. 66, no. 4, pp. 41-51, 1988.

[2] J. Li, C. Liu, X. Zeng, and N. Zhang, "Optimization and coordination of crowdsourcing supply chain in fast fashion industry," Mathematical Problems in Engineering, vol. 2018, Article ID 8123169, 16 pages, 2018.

[3] M. Sarkar, H. Sun, and B. Sarkar, "Effects of variable production rate and time-dependent holding cost for complementary products in supply chain model," Mathematical Problems in Engineering, vol. 2017, Article ID 2825103, 13 pages, 2017.

[4] S. T. Zhao, X.-M. Wu, and Y. Yuan, "Optimal productioninventory policy for an integrated multi-stage supply chain with time-varying demand," European Journal of Operational Research, vol. 255, no. 2, pp. 364-379, 2016.

[5] H. K. Chen and H. W. Chou, "A time-dependent supply chain network equilibrium problem," in Global Integrated Supply Chain Systems, Y. C. Lan and B. Unhelkar, Eds., pp. 217-242, Idea Group Inc., Calgary, Canada, 2006.

[6] A. Nagurney, Z. Liu, M. G. Cojocaru, and P. Daniele, "Dynamic electric power supply chains and transportation networks: an evolutionary variational inequality formulation," Transportation Research Part E, vol. 43, no. 5, pp. 626-646, 2007.

[7] X. Peng and Y. Zhang, "On dynamic equilibrium model of supply chain networks with time-varying demand," Systems Engineering-Theory \& Practice, vol. 33, no. 5, pp. 1158-1166, 2013.

[8] J. N. Su, C. G. Liu, and Y. Yin, "Optimization and coordination for short-life-cycle product supply chain with double-varying parameters of forecast accuracy and cost," Chinese Journal of Management Science, vol. 23, no. 10, pp. 107-112, 2015.

[9] L. L. Hou and W. H. Qiu, "Option contract design for a supply chain under price-dependent stochastic demand," Journal of Liaoning Technical University (Natural Science), vol. 28, no. 1, pp. 127-130, 2009.

[10] S. Ray, S. Li, and Y. Song, "Tailored supply chain decision making under price-sensitive stochastic demand and delivery uncertainty," Management Science, vol. 51, no. 12, pp. 1873-1891, 2005.

[11] K.-J. Chung and C.-N. Lin, "Optimal inventory replenishment models for deteriorating items taking account of time discounting," Computers \& Operations Research, vol. 28, no. 1, pp. 67-83, 2001.

[12] B. Luo, B. Huang, and N. Lu, "A vendor-managed inventory model with linear time varying," Systems Engineering-Theory \& Practice, vol. 5, no. 5, pp. 36-41, 2006.

[13] S. H. Ma and F. S. Wang, "Study on the decision mode of supply chain for time-sensitive and price-sensitive demand," Chinese Journal of Management Science, vol. 14, no. 3, pp. 13-19, 2006.

[14] J. N. Su, J. H. Chen, and B. H. Yang, "A game analysis of short life-cycle products supply chain with time-based parameters," Journal of Systems \& Management, vol. 18, no. 4, pp. 436-442, 2009.

[15] J. N. Su, J. H. Chen, and C. G. Liu, "Coordination of timevarying price supply chain under uncertain response time," Systems Engineering-Theory \& Practice, vol. 31, no. 3, pp. 461-470, 2011.

[16] F. Ye and Q. Lin, "Revenue sharing contract mechanisms of risk-averse supply chains," Journal of Industrial Engineering and Management, vol. 26, no. 1, pp. 113-118, 2012.

[17] Q. Lin, F. Ye, and X. M. Chen, "Decision modes for supply chain based on CVaR and revenue sharing contract under stochastic elastic demand," Systems Engineering-Theory \& Practice, vol. 31, no. 12, pp. 2296-2307, 2011.

[18] H. Wang and J. Zhou, "Optimal strategies of dual channel with risk averse members," Computer Integrated Manufacturing Systems, vol. 15, no. 11, pp. 2241-2246, 2009.

[19] L. L. Zhang and Z. Yao, "Optimal strategy of risk-averse dualchannel supply chain with consumer returns," Computer Integrated Manufacturing Systems, vol. 21, no. 3, pp. 766-775, 2015.

[20] J. F. Li, S. P. Chen, Z. Q. Huang, and Y. B. Tang, "Logistic service supply chain coordination based on option and in- 
tegrator risk aversion," Computer Integrated Manufacturing Systems, vol. 19, no. 5, pp. 1105-1114, 2013.

[21] Y.-J. Zhou, X.-H. Chen, and Z.-R. Wang, "Optimal ordering quantities for multi-products with stochastic demand: returnCVaR model," International Journal of Production Economics, vol. 112 , no. 2, pp. 782-795, 2008.

[22] C. X. Wang, “The loss-averse newsvendor game," International Journal of Production Economics, vol. 124, no. 2, pp. 448-452, 2010.

[23] P. Gao, J. J. Nie, and Z. Q. Xie, "Patent authorization strategy of closed-loop supply chain under manufacturer risk aversion," Computer Integrated Manufacturing Systems, vol. 20, no. 3, pp. 680-688, 2014.

[24] X. G. Cao, B. R. Zheng, H. S. Xia, J. Z. Li, and H. Wen, "Analysis on closed-loop supply chain network equilibrium with risk-averse retailers," Control and Decision, vol. 29, no. 4, pp. 659-665, 2014.

[25] Z. Long, J. S. Shi, and W. U. Cheng, "Supply chain coordination of loss-averse newsvendor with contract," Tsinghua Science and Technology, vol. 10, no. 2, pp. 133-140, 2005.

[26] L. Yang, M. Xu, G. Yu, and H. Zhang, "Supply chain coordination with CVaR criterion," Asia-Pacific Journal of Operational Research, vol. 26, no. 1, pp. 135-160, 2009.

[27] H. M. Wee, "A deterministic lot-size inventory model for deteriorating items with shortages and a declining market," Computers \& Operations Research, vol. 22, no. 3, pp. 345-356, 1995.

[28] M. E. Schweitzer and G. P. Cachon, "Decision bias in the newsvendor problem with a known demand distribution: experimental evidence," Management Science, vol. 46, no. 3, pp. 404-420, 2000.

[29] S. J. Zhang, S. J. Song, and G. S. Xu, "Coordination of timevarying price supply chain with risk-averse retailers," Computer Integrated Manufacturing Systems, vol. 21, no. 5, pp. 1375-1381, 2015. 